\title{
Flape cutâneo em padrão axial auricular caudal para correção de defeito extenso após extirpação de fibrossarcoma facial em felino
}

\author{
[Use of a caudal auricular axial pattern flap for correction of large defect after facial \\ fribrosarcoma extirpation in a cat] \\ Í.S. Dal-Bó ${ }^{1}$, M.V. Brun ${ }^{2 *}$, C.E. Bortolini ${ }^{1}$, A.M. Quadros ${ }^{1}$, J.A.B. Chagas $^{1}$ \\ ${ }^{1}$ Hospital Veterinário - Universidade de Passo Fundo - HV-UPF - Passo Fundo, RS \\ ${ }^{2}$ Universidade Federal de Santa Maria - UFSM - Santa Maria, RS
}

\begin{abstract}
RESUMO
Um felino que apresentava massa de grandes dimensões, localizada no lábio superior direito, foi submetido à cirurgia para exérese do aumento de volume mantendo-se margem de tecido sadio. $\mathrm{O}$ defeito facial foi reconstituído com um flape cutâneo em padrão axial auricular caudal. A ferida apresentou cicatrização em primeira intenção em sua maior extensão, com adequados resultados cosmético e funcional. A avaliação histopatológica revelou se tratar de fibrossarcoma, o qual não apresentou recidivas locais pelo período mínimo de 21 meses de pós-operatório.
\end{abstract}

Palavras-chave: cirurgia plástica, cirurgia reconstrutiva, neoplasias

\begin{abstract}
A cat presented for clinical evaluation with a large mass on the superior lip was submitted to surgery to remove the tumor with the conservation of healthy tissue around it. The facial defect was reconstructed with a cutaneous flap in the caudal auricular axial pattern. The wound presented first intention healing on the major extension, with adequate functional and cosmetic results. According to the histopathological findings, it was a fibrosarcoma, which did not show any sign of relapse in the next 21 months after the surgical intervention.
\end{abstract}

Keywords: plastic surgery, reconstructive surgery, neoplasms

\section{INTRODUÇÃO}

O fibrossarcoma é classificado como neoplasia mesenquimal maligna que se origina a partir dos fibroblastos. Possui comportamento localmente infiltrativo, com baixo potencial metastático, porém são comuns recidivas após a remoção cirúrgica (Müller et al., 2009). Geralmente se apresenta como massa solitária e indolor, localizando-se principalmente na pele, no tecido subcutâneo e na cavidade oral (Aguiar et al., 2009). A ocorrência de fibrossarcomas é comum em cães e gatos, sendo responsáveis por 15 a $17 \%$ das neoplasias cutâneas nesses animais e representando o quarto tipo de tumor cutâneo mais comum nessas espécies (Raskin, 2003). Em geral, em gatos está associado à administração subcutânea e intramuscular de vacinas, fármacos, fluidoterapia e anti-pulgas injetáveis, sendo também denominado "sarcoma de aplicação felino” (Séguin, 2002; Carneiro et al., 2008).

O tratamento é baseado na terapia multimodal, envolvendo cirurgia, radioterapia e quimioterapia (Carneiro et al., 2008). O planejamento da ressecção cirúrgica e da oclusão do defeito é baseado na localização, no tamanho e no grau de diferenciação da neoplasia, sendo recomendadas margens cirúrgicas amplas de 2 a $3 \mathrm{~cm}$ (largura, comprimento e profundidade) para a exérese de sarcomas de tecidos moles (Dernell et al., 1998).

Recebido em 26 de junho de 2012

Aceito em 8 de maio de 2013

*Autor para correspondência (corresponding author)

E-mail: mauriciovelosobrun@hotmail.com 
A remoção de neoplasias faciais resulta em grandes defeitos cutâneos e, geralmente, na impossibilidade de oclusão primária devido à tensão na linha de sutura. A pele dessa região é relativamente imóvel em comparação às regiões occipital e do tronco, portanto alterações funcionais ou cosméticas podem ser observadas após cicatrização por segunda intenção ou após a realização de retalhos de avanço (Fahie e Smith, 1997; Milgram et al., 2011). Esses últimos dependem unicamente do plexo subdérmico, já os axiais promovem vascularização de uma grande área cutânea, uma vez que são nutridos por pedículo arterial, sendo considerados superiores aos de avanço (Fahie e Smith, 1997).

\section{RELATO DE CASO}

Foi atendido, no Hospital Veterinário da Universidade de Passo Fundo (HV-UPF), um felino, SRD, fêmea, adulta, de 2,6kg, apresentando uma massa localizada no lábio superior direito, de aproximadamente $3,5 \mathrm{~cm}$ de diâmetro (Fig. 1 - A e B). O proprietário desconhecia o tempo de evolução da massa, uma vez que havia adotado recentemente o animal. Ao exame físico, havia aumento do linfonodo mandibular direito, e a neoplasia era de consistência macia, alopécica, ulcerativa, apresentando crostas e secreção serosa. Não havia, contudo, alterações nos parâmetros fisiológicos (temperatura retal, frequências cardíaca e respiratória, tempo de preenchimento capilar, pulso femoral e coloração de mucosas). Na pesquisa de possíveis metástases, foram realizadas radiografias de tórax $\mathrm{e}$ ultrassonografia abdominal, a partir das quais não se constataram alterações. Os resultados dos exames pré-operatórios (dosagens séricas de albumina, ALT, FA, ureia e creatinina) estavam dentro dos parâmetros fisiológicos para a espécie. Já o hemograma revelou leucocitose (20.800 leucócitos totais). A análise citológica demonstrou presença de células inflamatórias, ausência de celularidade e de agentes infecciosos. Foram realizadas radiografias de crânio, as quais não revelaram comprometimento ósseo. Optou-se por submeter o paciente à exérese da massa, seguida de cirurgia plástica e reconstrutiva. A medicação pré-anestésica utilizada foi a associação de cetamina $\left(8 \mathrm{mg} \cdot \mathrm{kg}^{-1}\right)$, midazolam $\left(0,5 \mathrm{mg} \cdot \mathrm{kg}^{-1}\right)$, morfina $\left(0,5 \mathrm{mg} \cdot \mathrm{kg}^{-1}\right)$ e acepromazina $\left(0,03 \mathrm{mg} \cdot \mathrm{kg}^{-1}\right)$, por via intramuscular. Para indução, foi usado propofol $\left(4 \mathrm{mg} \cdot \mathrm{kg}^{-1}\right)$ por via endovenosa e, para manutenção, isofluorano foi vaporizado em oxigênio a $100 \%$ em sistema aberto.

A exérese da neoplasia foi realizada a partir de uma incisão elíptica para a remoção do lábio superior direito, com margem de segurança de, aproximadamente, $1 \mathrm{~cm}$. Os vasos associados ao tumor foram ligados com fio poliglactina 910 4-0 e ligadura transfixante e, em seguida, seccionados (Fig. 1 - C). A partir da ferida obtida, realizou-se biópsia do linfonodo mandibular direito devido ao seu aumento de volume. Macroscopicamente, não havia sinais de neoplasia envolvendo tal linfonodo.

Para reparo do defeito causado pela remoção da neoplasia, foi confeccionado um flape cutâneo em padrão axial auricular caudal. A base do flape estava localizada sobre a zona lateral da asa direita do atlas. Foi traçada uma linha incisional caudal paralela à base, em um ponto rostral à espinha da escápula direita. Após, foram traçadas as linhas dorsal e ventral, que se conectavam com a linha incisional caudal em uma largura que permitia a síntese do sítio doador. Essas linhas foram incisadas e o flape foi elevado na profundidade do platisma, até a identificação dos ramos esternocleidomastoideos da artéria auricular caudal. O flape foi rotacionado em sentido craniolateral até cobrir completamente o defeito causado pela exérese da neoplasia. O retalho cutâneo foi, então, suturado ao leito receptor em padrão walking suture, com fio poliglactina $9104-0$, sendo os pontos intercalados, sem abranger os ramos dos vasos cutâneos direitos auriculares caudais. Já a aposição das bordas cutâneas do defeito e do flape foi realizada por meio de suturas interrompidas simples, com fio de náilon monofilamentar 5-0 (Fig. 1 - D, E e F). A redução do defeito associado ao leito doador foi realizada também em padrão walking suture usando-se fio poliglactina 910 4-0. A síntese cutânea dessa área foi obtida com fio náilon monofilamentar 5-0 em padrão isolado simples. 


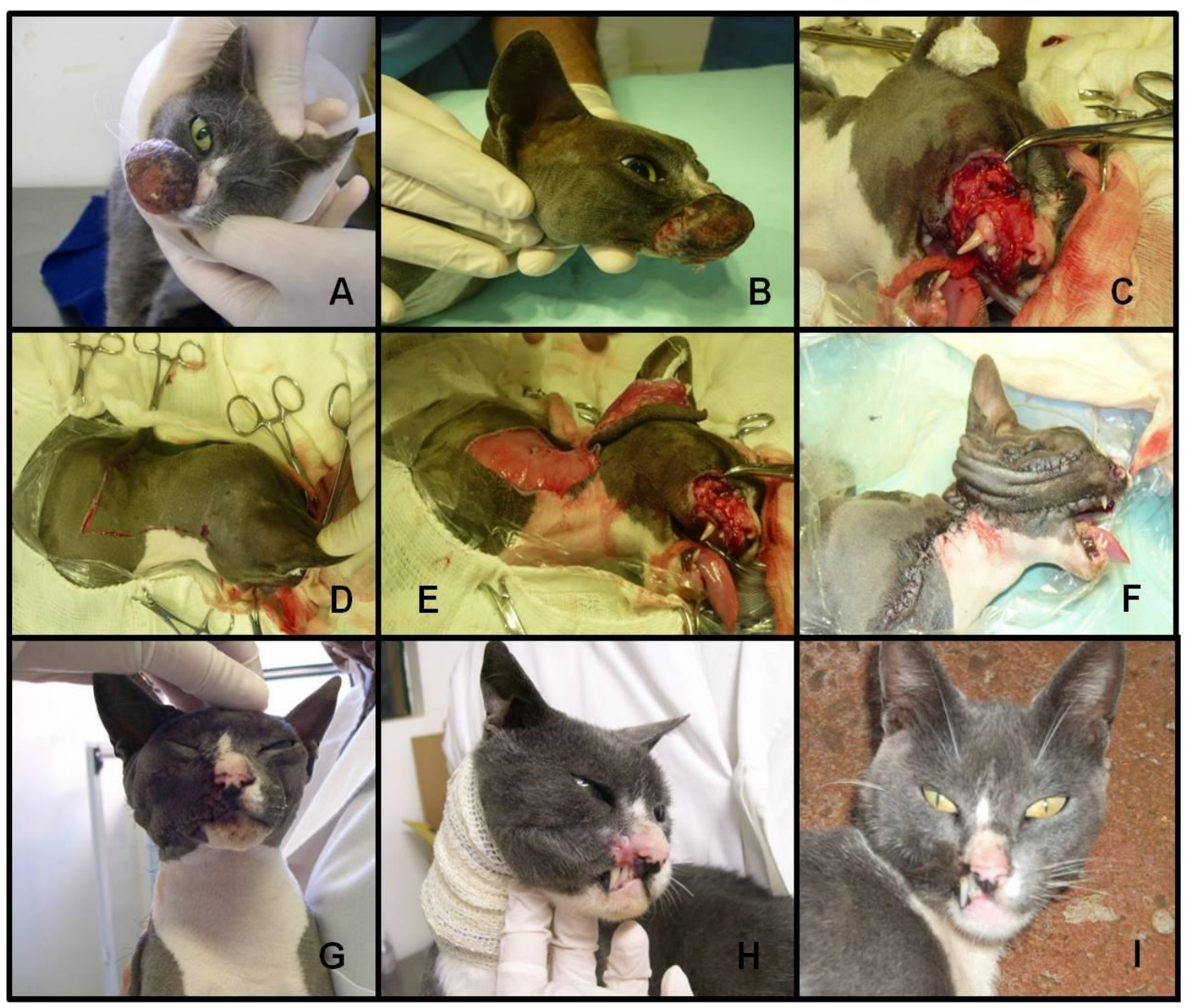

Figura 1: A e B - Felino, SRD, fêmea, adulta, de 2,6kg, apresentando uma massa localizada no lábio superior direito, de aproximadamente $3,5 \mathrm{~cm}$ de diâmetro, de consistência macia, alopécica, ulcerativa, com crostas e secreção serosa. C - Defeito causado pela remoção da neoplasia. D e E - Confecção do flape em padrão axial auricular caudal. F - Aspecto final da intervenção cirúrgica. G - Ferida cirúrgica no primeiro dia de pós-operatório. H - Ferida cirúrgica aos 24 dias de pós-operatório. I - Paciente aos 21 meses após a intervenção cirúrgica. Notar adequado resultado cosmético e funcional, contudo com diferença de orientação e comprimento dos pelos na região do flape em relação aos da face.

Como medicações pós-operatórias, utilizou-se cefalotina (30mg. $\mathrm{kg}^{-1}$, TID, sete dias, IV), cloridrato de tramadol $\left(2 \mathrm{mg} \cdot \mathrm{kg}^{-1}\right.$, TID, quatro dias, SC) e meloxicam $\left(0,1 \mathrm{mg} \cdot \mathrm{kg}^{-1}\right.$, SID, três dias, SC). O paciente permaneceu internado para realização de limpeza da ferida cirúrgica e de curativos com atadura (Fig. $1-\mathrm{G}$ e $\mathrm{H}$ ) por 15 dias, além de ser mantido permanentemente com colar elizabetano. Por meio de contato telefônico, 21 meses após a ressecção cirúrgica do tumor, o proprietário relatou que o animal se encontrava em bom estado geral e que não houve recidivas locais da neoplasia (Fig. $1-\mathrm{I}$ ).
O exame histopatológico da neoplasia revelou epiderme com área focal ulcerada com infiltrado neutrofílico e linfócitos em menor número. Havia extensa proliferação moderadamente invasiva de células neoplásicas arranjadas em um manto de células (que, em algumas áreas, formavam redemoinhos) com citoplasma fusiforme, fracamente eosinofílico, homogêneo e indistinto, e núcleos alongados e densos na derme. As células neoplásicas eram moderadamente diferenciadas e algumas apresentavam citoplasma alongado ou oval e núcleos redondos e grandes formados por cromatina frouxa. Havia áreas multifocais de 
necrose em meio à massa tumoral. Todas essas alterações permitiram o diagnóstico de fibrossarcoma bem diferenciado. O exame histopatológico do linfonodo não apresentou alterações.

\section{DISCUSSÃO}

Em geral, os fibrossarcomas em felinos estão associados à administração de fármacos ou vacinas via subcutânea e podem se desenvolver no intervalo de três meses a três anos após a aplicação (Müller et al., 2009). Já os fibrossarcomas obervados em gatos jovens e que não possuem histórico de aplicações podem ser causados pelo vírus da leucemia felina e tendem a ser múltiplos (Raskin, 2003). No felino deste caso, porém, não havia conhecimento do histórico do tempo de evolução ou de alguma aplicação, visto que o animal havia sido adotado recentemente. Supõe-se, no entanto, que o fibrossarcoma tenha se desenvolvido em resposta à inflamação crônica, já que a região da face não é um local comum para administrações medicamentosas.

Citologicamente, os fibrossarcomas são caracterizados por várias células gigantes dilatadas, individuais ou agregadas, frequentemente em associação com material colagenoso róseo. Ocasionalmente podem ser observadas células gigantes multinucleadas. $\mathrm{O}$ pleomorfismo nuclear é marcante e as células apresentam-se uniformes e mostram alta proporção núcleo:citoplasma (Raskin, 2003). Entretanto, a análise citológica na neoplasia do presente caso não mostrou nenhuma dessas características, talvez por colheita inapropriada do material ou, então, por características inerentes às neoplasias mesenquimais, como, por exemplo, baixa celularidade devido à presença de grande quantidade de tecido conjuntivo fibroso na matriz extracelular (Thall, 2007). O diagnóstico só pode ser estabelecido por meio do exame histopatológico.

O tratamento de escolha para o fibrossarcoma é o cirúrgico. A remoção da neoplasia requer margens de segurança amplas em todos os planos, o que geralmente leva à criação de grande defeito cutâneo, dificultando ou impossibilitando a aproximação direta das bordas (Aguiar et al., 2009). Tal condição também foi constatada no presente relato. A localização do defeito em relação aos órgãos de visão e audição não possibilitou a obtenção de margens de ressecção tão amplas quanto 2 a $3 \mathrm{~cm}$ distantes do tumor (Lidbetter et al., 2002). Contudo, nesse paciente, a margem de aproximadamente $1 \mathrm{~cm}$ demonstrou ser eficiente, já que permitiu apropriado resultado funcional, sem que ocorresse recidiva local pelo período mínimo de 21 meses.

Uma alternativa para correção desse tipo de defeito extenso são os flapes cutâneos em padrão axial, os quais incluem uma artéria e uma veia cutânea direta em sua base, sendo que os ramos terminais desses vasos suprem o plexo subdérmico (Hedlund, 2005; Milgram et al., 2011). Nesse caso, os autores optaram pelo padrão axial por ser superior ao pediculado em relação à condição circulatória, uma vez que este último possui irrigação e drenagem apenas a partir do plexo subdérmico. Ponderou-se que a condição circulatória de um retalho pediculado poderia interferir em sua incorporação numa ferida facial tão ampla.

O manejo pós-operatório, entretanto, foi dificultado em razão do temperamento ativo do paciente e da localização da ferida, uma vez que a viabilidade do flape depende da manutenção de um ambiente imóvel para que haja incorporação. Ainda que o animal tenha sido mantido com atadura, recobrindo a maior parte da ferida cirúrgica, associada ao colar elizabetano até a retirada dos pontos, ocorreu deiscência de apenas pequena área de defeito junto à extremidade medial do retalho, a qual estava em contato com a narina e a cavidade oral e acabava por acumular resíduos alimentares. Essa ferida póscirúrgica foi, então, manejada com limpeza com solução de $\mathrm{NaCl}$ a $0,9 \%$ três vezes ao dia e após as refeições, sendo que ela apresentou cicatrização em segunda intenção. Deiscência de flapes de padrão axial em pequenos animais são comuns (Milgram et al., 2011), e no paciente relatado considerou-se a obtenção de excelente resultado quanto a esse aspecto, já que houve cicatrização em primeira intenção envolvendo a maior parte do retalho.

Acredita-se que o tratamento cirúrgico foi curativo, pois não houve recidiva da neoplasia em pelo menos 21 meses de pós-operatório, já que a média de tempo para que ocorra recidiva é de 66 dias (Hershey et al., 2000). Assim, 
conclui-se que a reconstrução cirúrgica de defeitos faciais pós-extirpação de fibrossarcoma em gatos pode ser obtida com flape de padrão axial caudal, mantendo-se adequados resultados funcionais e cosméticos.

\section{REFERÊNCIAS}

AGUIAR, J.; OLIVEIRA, L.O.; OLIVEIRA, R.T. et al. Fibrossarcoma de aplicação em felinos: relato de três casos. Medvep - Rev. Cient. Med. Vet. - Peq. Anim. e Anim. Estimação, v.7, p.209-213, 2009.

CARNEIRO, C.S.; QUEIROZ, G.F.; ZERWES, M.B.C. et al. Sarcoma de aplicação felino. Semina: Cienc. Agrárias, v.29, p.921-932, 2008.

DERNELL, W.S.; WITHROW, S.J.; KUNTZ, C.A. et al. Principles of treatment for soft tissue sarcoma. Clin. Tech. Small Anim. Pract., v.13, p.59-64, 1998.

FAHIE, M.A.; SMITH, M.M. Axial pattern flap based on the superficial temporal artery in cats: an experimental study. Vet. Surg., v.26, p.86-89, 1997.

HEDLUND, C.S. Cirurgia do sistema tegumentar. In: FOSSUM, TW. Cirurgia de Pequenos Animais. 2.ed. São Paulo: Ed. ROCA, 2005. p. 135-230.

HERSHEY, A.E.; SORENMO, K.U; HENDRICK, M.J. et al. Prognosis for presumed feline vaccineassociated sarcoma after excision: 61 cases (1986-1996). J. Am. Vet. Med. Assoc., v.216, p.58-61, 2000.
LIDBETTER, D.A.; WILLIAMS, F.A.; KRAHWINKEL, D.J. et al. Radical lateral body-wall resection for fibrosarcoma with reconstruction using polypropylene mesh and a caudal superficial epigastric axial pattern flap: a prospective clinical study of the technique and results in 6 cats. Vet. Surg., v.31, p.57-64, 2002.

MILGRAM, J.; WEISER, M.; KELMER, E. et al. Axial pattern flap based on a cutaneous branch of the facial artery in cats. Vet. Surg., v.40, p.347-351, 2011.

MÜLLER, D.C.M.; MORAES, A.A.; GARCIA, E.F.V. et al. Reconstrução da parede tóracoabdominal com malha de polipropileno, após remoção de fibrossarcoma. Medvep - Rev. Cient. Med. Vet. - Peq. Anim. e Anim. Estimação, v.7, p.517-521, 2009.

RASKIN, R.E. Pele e tecido subcutâneo. In: RASKIN, R.E.; MEYER, D.J. Atlas de Citologia de Cães e Gatos. São Paulo: ROCA, 2003. p.29-78.

SÉGUIN, B. Feline injection site sarcomas. Vet. Clin. Small. Anim., v.32, p.983-995, 2002.

THRALL, M.A. Diagnostic citology in clinical oncology. In: WITHROW, S.J.; MACEWEN, E.G. Small Animal Clinical Oncology. 4.ed. St. Louis: SAUNDERS ELSEVIER, 2007. p.112133. 